\title{
Pathogenesis of polycystic ovary syndrome: multifactorial assessment from the foetal stage to menopause
}

\author{
Anderson Sanches de Melo ${ }^{1}$, Sabrine Vilan Dias ${ }^{1}$, Ricardo de Carvalho Cavalli ${ }^{1}$, \\ Viviane Cunha Cardoso ${ }^{2}$, Heloisa Bettiol ${ }^{2}$, Marco Antonio Barbieri ${ }^{2}$, Rui Alberto Ferriani ${ }^{1}$ \\ and Carolina Sales Vieira ${ }^{1}$ \\ ${ }^{1}$ Unit of Human Reproduction and Gynecological Endocrinology, Department of Gynecology and Obstetrics and \\ ${ }^{2}$ Department of Paediatrics, Medical School of Ribeirão Preto, University of São Paulo, Avenida Bandeirantes, \\ 3900 - Campus Universitário - Monte Alegre, CEP: 14049-900, Ribeirão Preto, São Paulo, Brazil
}

Correspondence should be addressed to A S Melo; Email: doctor_asmelo@yahoo.com.br

\begin{abstract}
Polycystic ovary syndrome (PCOS) is a multifactorial disorder that arises from interactions between genetic, environmental and intrauterine factors. Small-for-gestational-age (SGA) babies and the daughters of mothers with PCOS represent possible postnatal clinical targets for developmental programming by steroid excess. The presence of excess glucocorticoids and/or androgens during foetal organogenesis and growth might promote changes in gene expression, and these changes might be related to an increase in the risk of PCOS-like reproductive and metabolic disorders in postnatal life, such as rapid growth and weight gain during the first 2 years of life (only in SGA babies), hyperinsulinaemia, adipocyte dysfunction and childhood visceral obesity, premature pubarche and adrenarche (only in SGA babies) and PCOS. In the fourth decade of life, women who have PCOS may be at higher risk for type 2 diabetes mellitus, dyslipidaemia and systemic arterial hypertension, which suggests that these women are also at higher risk for cardiovascular disease during menopause. However, PCOS can also occur in women who were born at appropriate weight for GA or in newborns of women without PCOS, which suggests that genetic variation and environmental factors play important roles in the development and maintenance of PCOS in a population. Genome-wide association studies based on adequate population samples have shown a higher frequency of genetic polymorphisms of the LHCGR, THADA and DENND1A genes in women with PCOS. Genetic studies of PCOS have also included analyses of structural changes in the chromosome based on an assessment of telomere length in single, cross-sectional evaluations, and these studies have produced controversial results. The present narrative review assesses the multifactorial origins of PCOS (including environmental, genetic and intra-uterine factors) and the development of conditions associated with this disorder. It is concluded that although PCOS might originate in the intra-uterine environment through developmental programming by steroid excess, the interaction between genetic and environmental factors is crucial for its appearance. Follow-up studies should be conducted to assess the same populations over their entire lifespans while taking into account different aspects of the pathogenesis of PCOS.
\end{abstract}

Reproduction (2015) 150 R11-R24

\section{Introduction}

Polycystic ovary syndrome (PCOS) is a heterogeneous and complex endocrine disorder with an estimated prevalence of $5-13.9 \%$ in women of reproductive age (Norman et al. 2007, Melo et al. 2010). In addition to causing reproductive disorders (anovulation and infertility), PCOS may or may not have a clinical and metabolic impact that varies according to ethnicity and geographic region (Tian et al. 2006, Norman et al. 2007).

Although the clinical manifestations of PCOS appear in adolescence, it has been suggested that the disease has its origins in the intra-uterine environment (de Zegher \& Ibáñez 2006). Experimental studies in animals (Abbott et al. 2002, 2005) and clinical observations in human subjects (Melo et al. 2010) lend support to the hypothesis that developmental programming by steroid excess plays a role in the development of PCOS and its associated disorders at various stages of life (Jaquet et al. 2005) (Fig. 1). However, because the interaction between postnatal environmental factors and genetic predisposition are crucial for its occurrence, PCOS clearly has a multifactorial aetiology.

The developmental programming of PCOS represents changes in gene expression that occur following exposure to steroids (mainly glucocorticoids and/or androgens) during critical periods of foetal development. Some evidence suggests that this phenomenon is associated with variable PCOS-related metabolic and reproductive phenotypes in extra-uterine life and that these phenotypes are associated with the stage of 


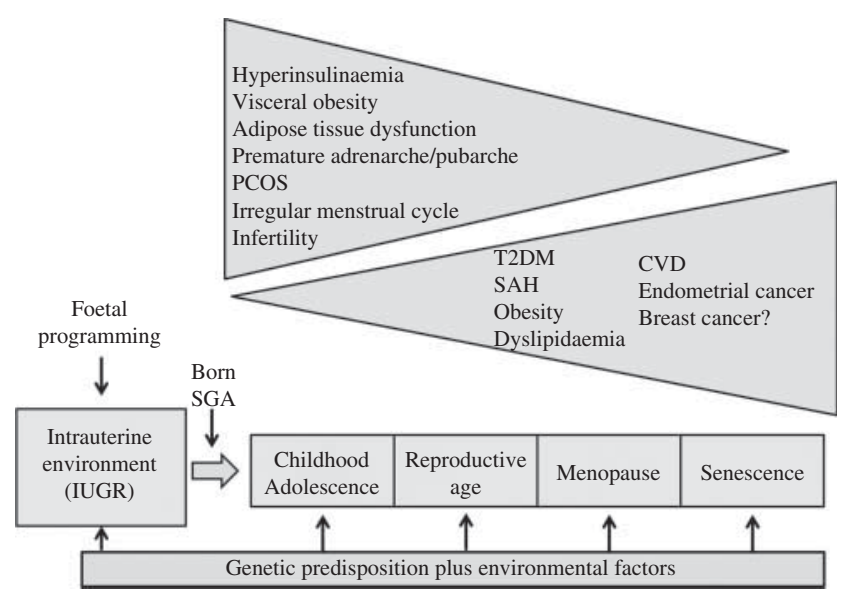

Figure 1 Natural history of PCOS. PCOS has a multifactorial aetiology that includes intra-uterine, genetic and environmental factors which might or might not be interrelated. Although the clinical manifestations of PCOS appear in adolescence, it has been suggested that the natural history of the disease has its origins in the intra-uterine environment through developmental programming. This process might be associated with several of the PCOS-related clinical and metabolic disorders that occur at different stages of life as a function of the type and duration of an individual's exposure to postnatal environmental factors.

In addition, other mechanisms (such as genetic predisposition) might play a role in the origin of PCOS, seeing as individuals who allegedly do not undergo developmental programming (appropriate-for-gestationalage subjects or daughters of women without PCOS) can also develop PCOS and its associated comorbidities. Adapted from Galluzzo et al. (2008). IUGR, intra-uterine growth restriction; SGA, small for gestational age; T2DM, type 2 diabetes mellitus; $\mathrm{SAH}$, systemic arterial hypertension; CVD, cardiovascular disease.

pregnancy during which the foetus was exposed to excess steroids (Padmanabhan \& Veiga-Lopez 2011, Reynolds et al. 2012).

Developmental programming by glucocorticoid excess might account for the higher risk of PCOS and the associated clinical-metabolic disorders exhibited by small-for-gestational-age (SGA) infants who present compensatory growth. Although women who were born SGA may have an increased risk for developing PCOS, and both PCOS and SGA may lead to a higher risk of cardiovascular disease during old age (Jaquet et al. 2005, Martinez-Aguayo et al. 2007, Bonamy et al. 2008, Anderson et al. 2014), these propositions have not been evaluated in follow-up studies that simultaneously considered subjects who were born SGA and those who had PCOS. Thus, it is possible that individuals born SGA who exhibit compensatory growth, PCOS and cardiovascular and metabolic alterations represent part of a spectrum of abnormalities in developmental programming due to steroid excess.

Developmental programming by androgen excess during pregnancy could occur in women with obesity, type 2 diabetes mellitus (DM), insulin resistance (IR) (Escobar-Morreale et al. 2014), excessive weight gain during pregnancy, PCOS and/or any other situation associated with hyperandrogenism (Sir-Petermann et al.
2009) and could result in an increased risk of PCOS and/ or associated clinical and metabolic comorbidities in their offspring (Sir-Petermann et al. 2009, Padmanabhan \& Veiga-Lopez 2011, Escobar-Morreale et al. 2014). Experimental studies show that androgen excess during intra-uterine development may also be associated with intra-uterine growth restriction (IUGR) (Beckett et al. 2014), hyperinsulinaemia, visceral obesity in childhood and PCOS-like reproductive manifestations in women of reproductive age (Abbott et al. 2005, Padmanabhan \& Veiga-Lopez 2011). Notwithstanding this association, individuals who apparently did not undergo developmental programming (subjects with birth weights appropriate for their gestational age (AGA) and daughters of women without hyperandrogenism during pregnancy) can also develop PCOS (Melo et al. 2010). This observation suggests that genetic variation and environmental factors play important roles in the development of PCOS. Genome-wide association studies (GWAS) have shown a higher frequency of genetic polymorphisms of the LHCGR, THADA and DENND1A genes in women with PCOS (Chen et al. 2011, Shi et al. 2012, Louwers et al. 2013). Genetic factors associated with a higher frequency of PCOS also include structural changes in chromosomes that have been analysed in cross-sectional studies by assessing telomere length at a single time point. These analyses have presented controversial results, and additional studies involving the longitudinal assessment of telomere length dynamics in women with PCOS at different stages of life are needed.

Existing studies of the pathogenesis of PCOS have limitations. Because there are three supported definitions of PCOS (Zawadski \& Dunaif 1992, Rotterdam ESHRE/ASRM-Sponsored PCOS Consensus Workshop Group 2004, Azziz et al. 2006), comparing the results reported in different publications is somewhat difficult. Whereas some authors use a PCOS diagnosis based on criteria listed by the National Institutes of Health (NIH) (Goodarzi et al. 2012, Jones et al. 2012, Welt et al. 2012, Hwang et al. 2012, Mutharasan et al. 2013), others use the criteria proposed by the American Society of Human Reproduction/European Society of Human Reproduction and Embryology (Chen et al. 2011, Shi et al. 2012, Hwang et al. 2012, Louwers et al. 2013), which thereby intensifies discrepancies in the published work on the genetic analysis of PCOS. Some authors have not even attempted to standardise the diagnosis of PCOS (Davies et al. 2012, Hizli et al. 2012), and they include in their studies women with polycystic ovaries on ultrasonography only, a finding that alone does not increase the risk for PCOS-associated conditions (Cresswell et al. 1997), or they collect retrospective data from medical records that antedate the publication of the first consensus on PCOS by the $\mathrm{NIH}$ (Mumm et al. 2013). 
The Rotterdam consensus criteria for the diagnosis of PCOS (Rotterdam ESHRE/ASRM-Sponsored PCOS Consensus Workshop Group 2004) defines some nonhyperandrogenic phenotypes (menstrual irregularity plus polycystic ovaries) as non-existent diagnoses according to the criteria formulated by the NIH (Zawadski \& Dunaif 1992) and the Androgen Excess Society (Azziz et al. 2006). Because the cardio-metabolic profile of PCOS phenotypes characterised by hyperandrogenism and chronic anovulation is poorer, the inclusion of nonhyperandrogenic phenotypes might favour the occurrence of bias in the assessment of the aetiopathogenesis of PCOS and its relationship to cardiovascular comorbidities during late stages of life (Melo et al. 2011, Daan et al. 2014). Moreover, most of the existing studies are multicentre cross-sectional or case-control studies in which women at different stages of life and who have a varied prevalence of comorbidities associated with PCOS were analysed (Michelmore et al. 2001, Ibáñez et al. 2008, Legro et al. 2010, Chen et al. 2011, Hizli et al. 2012, Hwang et al. 2012, Jones et al. 2012, Shi et al. 2012, Louwers et al. 2013, Shayeb et al. 2014).

The ethnic and geographic heterogeneity of PCOS demonstrates that this disorder is associated with environmental factors (Amsterdam ESHRE/ASRM-Sponsored 3rd PCOS Consensus Workshop Group 2012). The identification of geographical variations in the morbidity profiles of women with PCOS is therefore essential for establishing preventive measures to improve their health. In this context, birth cohorts seem to minimise these limitations because they include women of the same age range who are exposed to similar social, cultural and geographic factors. Moreover, birth cohort studies favour the simultaneous and prospective assessment of a variety of environmental, genetic and intra-uterine factors that may be associated with the development of PCOS and its clinical/metabolic changes at all stages of a woman's life.

The aim of the present narrative review is to assess the multifactorial origins of PCOS and to explore how its origin involves the interaction of environmental, genetic and intra-uterine factors over a lifespan. With respect to genetic studies of PCOS, only GWAS published before November 2014 were included in the present review, because the external validity of the population case series of such studies is adequate. No study has yet assessed the environmental factors directly associated with PCOS, so articles on lifestyle modifications and theories based on experimental studies were considered. Articles were searched in the PubMed database relative to observational studies published in English from January 1990 to November 2014. The search keywords were (polycystic ovary syndrome AND (foetal programming OR genetic susceptibility)), (polycystic ovary syndrome AND foetal programming AND (androgen OR glucocorticoids)), (polycystic ovary syndrome AND (low birth weight
OR birth weight OR small for gestational age)), (polycystic ovary syndrome AND (association studies, genome-wide OR association study, genome-wide OR genome-wide association studies)) and (polycystic ovary syndrome AND (gene environment interaction OR environment OR lifestyle)). A total of 1114 articles were located. Of them, 16 observational studies were included in the present review; four of these were relevant to the genetic component of PCOS, and 12 were relevant to intra-uterine factors associated with PCOS.

\section{Environmental factors associated with PCOS}

Environmental factors associated with PCOS can be classified as prenatal (foetal developmental programming) or postnatal (diet, obesity, sedentary lifestyle, environmental toxins and prescription drugs) (Diamanti-Kandarakis et al. 2006). Evidence suggests that environmental stimuli can both mimic hormonal actions and activate pre-existing, predisposing factors that trigger the endocrine activity characteristic of PCOS (Escobar-Morreale et al. 2005, Norman et al. 2007). Dietary habits, exercise and cultural, social and economic factors might modify environmental exposure. For that reason, among others, the prevalence of the metabolic conditions associated with PCOS (obesity, metabolic syndrome and disorders of glucose metabolism) might vary as a function of the type of environmental exposure, especially in racially mixed populations that do not have a predominant genetic background. Thus, although environmental factors cannot be homogeneous in studies of the pathogenesis of PCOS in human subjects, the internal validity of such studies can be increased by including women of the same ethnicity who are from the same geographic area.

It has been suggested that PCOS presents a nongenetic inheritance pattern in populations with a poor lifestyle (high-saturated-fat diet, sedentary lifestyle, alcoholism and smoking). In such populations, changes in the foetal-placental unit, the onset of IUGR and the frequency of SGA newborns may occur. Hyperinsulinaemia and visceral obesity are more likely to develop during childhood and to culminate in a higher prevalence of IR, systemic arterial hypertension (SAH) and hyperandrogenism (Ibáñez et al. 2001) in reproductive-age women. During pregnancy, women who were born SGA also present a higher risk for placental disorders and the delivery of SGA newborns, which suggests a non-genetic inheritance pattern of PCOS. If they maintained a proper lifestyle throughout their childhood and their reproductive period, these women would not experience placental changes; thus, the process described earlier would be interrupted, and their children would be born AGA (Fig. 2) (EscobarMorreale et al. 2005). Studies of familial aggregation in 


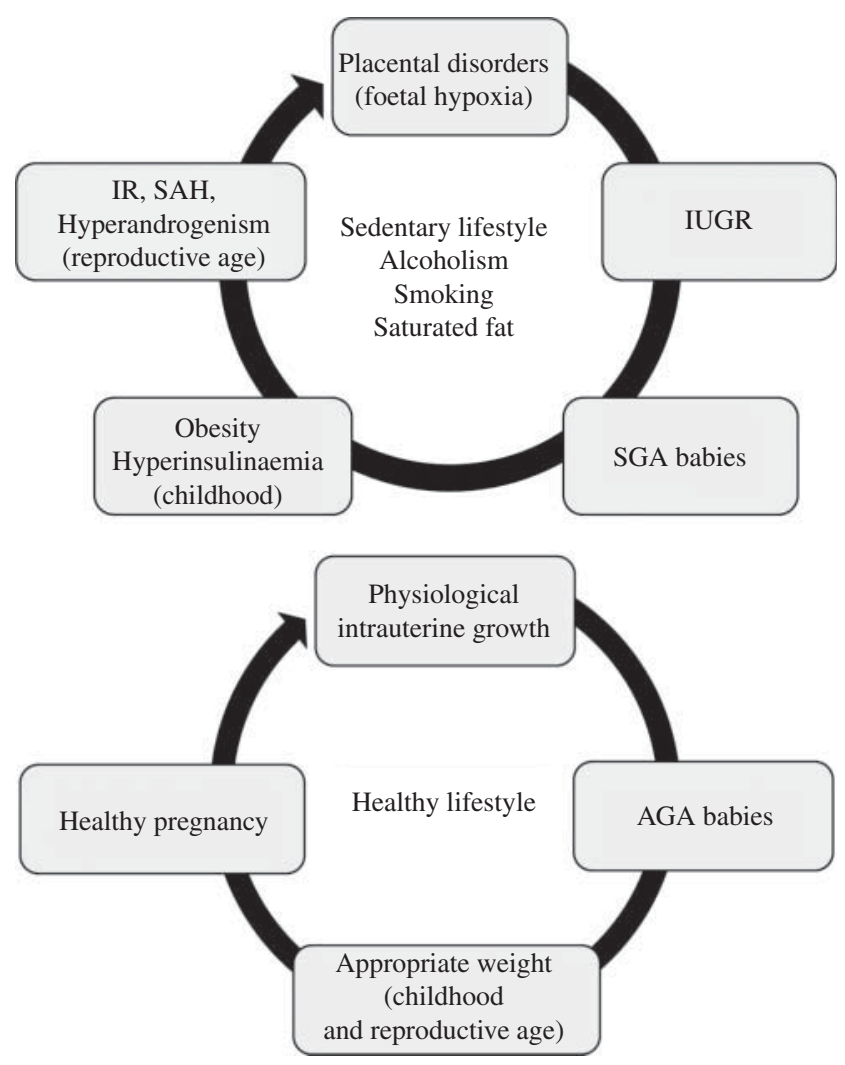

Figure 2 Environmental factors in the pathogenesis of polycystic ovary syndrome. Adapted from Escobar-Morreale et al. (2005). IUGR, intrauterine growth restriction; IR, insulin resistance; $\mathrm{SAH}$, systemic arterial hypertension; SGA, small for gestational age; AGA, appropriate for gestational age.

which different members of the same family are considered could establish the potential influence of the genetic component in the cascade of events described earlier.

The relevance of environmental factors to the development of PCOS is evidenced by the effect of lifestyle changes on obesity, which is a highly prevalent comorbidity among women with PCOS. Such measures might alter the phenotypic expression of PCOS. Reduction in body weight is the first line of treatment in obese women with PCOS. A loss of $2-5 \%$ of body weight reduces hyperinsulinaemia, increases sex hormone-binding globulin (SHBG) levels, reduces free androgen levels, restores the ovulatory cycle and improves clinical hyperandrogenism and metabolic disorders, such as dyslipidaemia (Thessaloniki ESHRE/ ASRM-Sponsored PCOS Consensus Workshop Group 2008, Moran et al. 2011). Contrarily, diets that are high in saturated fat and sedentary lifestyles are associated with the development of PCOS and its metabolic consequences, mainly obesity (Amsterdam ESHRE/ ASRM-Sponsored 3rd PCOS Consensus Workshop Group 2012).

\section{Genetic factors associated with PCOS}

Familial aggregation studies of PCOS suggest that it is an inherited disorder. Genetic inheritance of the condition has been demonstrated in studies of twins in which women with monozygotic twin sisters affected by PCOS were shown to have twice the risk of developing the disorder by the time they reached reproductive age (Vink et al. 2006). Studies of first-degree relatives of women with PCOS demonstrated an increased incidence of abnormal glucose metabolism and metabolic syndrome in men, which suggests a genetic background effect (Yildiz et al. 2003). Despite these considerations, the absence of a male PCOS phenotype, differences in the methodologies used in the studies, which were casecontrolled and did not consider the multifactorial aspects of the aetiology of PCOS, fertility problems in women with PCOS and the irreproducibility of the results obtained in non-familial studies limit the internal and external validity of current assessments of the genetic components of PCOS.

Although gene variants of hundreds of coding genes associated with the clinical and laboratory features of PCOS (genes related to hyperandrogenism, IR, SHBG, gonadotrophins, metabolic and inflammatory markers and obesity, among others) have been demonstrated in specific populations (Escobar-Morreale et al. 2005), these results present low external validity. A group of researchers from China conducted the first large GWAS on the human genome in Chinese women with PCOS and demonstrated a higher frequency of genetic polymorphism at 2 p16.3 (rs13405728), $2 \mathrm{p} 21$ (rs13429458) and 9q33.3 (rs2479106) in women with PCOS. These single-nucleotide polymorphisms (SNPs) were related to the following genes: LHCGR (the LH/ hCG receptor gene, which is associated with increased luteinising hormone (LH), enlarged ovaries, oligomenorrhea, resistance to $\mathrm{LH}$ or human chorionic gonadotrophin (HCG) and infertility), DENND1A (a gene that codes for a modifier of guanine that is associated with multiple organ dysfunction, including dysfunction of the ovary, hypothalamus, pituitary and adrenal glands and tissue-specific responses to insulin, type $2 \mathrm{DM}$ and obesity) and THADA (a thyroid adenoma gene associated with disorders of glucose metabolism, polycystic ovarian morphology, hypersecretion of $\mathrm{LH}$, hyperandrogenism and dyslipidaemia) in the PCOS group (Chen et al. 2011). However, the cases included in this initial evaluation were insufficient to establish genetic susceptibility to PCOS, which requires the evaluation of other polymorphisms in a larger sample. Subsequently, in 2254 cases of PCOS vs 3001 controls (women without PCOS), eight new loci were identified by the Chinese group. These included C9orf3, which is associated with hyperandrogenism and is located at 9q22.32 (rs3802457), YAP1, a gene associated with cell proliferation and apoptosis at 11q22.1 (rs1894116), RAB5B and 
SUOX, two genes associated with type $1 \mathrm{DM}$ at $12 \mathrm{q} 13.2$ (rs705702), HMGA2, a gene associated with infertility at 12q14.3 (rs22720), TOX3, a gene associated with DNA modification at 16q12.1 (rs4784165), INSR, a gene associated with IR at 19p13.3 (rs205980), SUMO1P1 and ZNF217, two genes associated with telomere dysfunction at 20q13.2 (rs6022786) and LHCGR at 2p16.3 (rs2268361). These new findings have demonstrated other genetic variants related to glucose metabolism disorders, sex hormone functions, insulin/ calcium signalling and endocytosis. The discovery of these new loci confirms the genetic predisposition to PCOS in Chinese women (Shi et al. 2012).

Although the findings obtained in Chinese populations have been confirmed in women with PCOS in the USA with respect to variants in the DENND1A (Goodarzi et al. 2012, Welt et al. 2012), THADA (Goodarzi et al. 2012), LHCGR and FSHR (Mutharasan et al. 2013) genes as well as in European populations (12 genetic variants in the LHCGR, THADA, DENND1A, FSHR, C9Orf3, YAP1, RAB5B/SUOX and
SUMO1P1 loci) (Louwers et al. 2013). A GWAS study conducted by a Korean group failed to confirm these results and found that only the glycogen synthase 2 (GYS2) gene could be linked to PCOS and its metabolic complications (Hwang et al. 2012). Another GWAS study conducted in the USA that analysed genes that code for proteins associated with metabolic and cardiovascular abnormalities also did not demonstrate a hereditary component of PCOS (Jones et al. 2012). These discrepancies may occur because genetic background varies according to ethnicity. Furthermore, some multicentre case-control studies included women at stages of life that ranged from adolescence to menopause who had heterogeneous social/cultural lifestyles and different clinical and metabolic manifestations of PCOS (certain patients were too young to present comorbidities). In addition, these studies did not consider other aspects of the pathogenesis of PCOS, such as birth weight and environmental factors. Table 1 presents data from GWAS studies of women with PCOS.

Table 1 Genome-wide association study in women with polycystic ovary syndrome ${ }^{\mathrm{a}}$.

\begin{tabular}{llll}
\hline Author & Population & Genes & Loci \\
\hline Chen et al. (2011) & PCOS: 744 vs control: 895 & DENND1A (9q33.3) & rs2479106 \\
(China) & Replication 1 & LHCGR $(2 \mathrm{p} 16.3)$ & rs13405728 \\
(GWAS1) & (North China) & THADA (2p21) &
\end{tabular}

PCOS: 2840 vs control: 5012

Replication 2

(South China)

PCOS: 498 vs control: 780

Shi et al. (2012)

(China)

(GWAS2)

and

(Meta-analysis GWAS1 and 2)

Jones et al. (2012)

(USA)

Hwang et al. (2012)

(Korea)

Louwers et al. (2013)

(The Netherlands/Dutch study)

and

(Meta-analysis of the population of USA, China and

The Netherlands)
GWAS2

PCOS: 1510 vs control: 2106

Meta-analysis

(GWAS1 and 2)

PCOS: 2254 vs control: 3001

PCOS: 443 vs control: 193

PCOS: 774 vs control: 967

Dutch study

PCOS: 703 vs control: 2164

Meta-analysis

(USA, China and The Netherlands) PCOS: 2254 vs control: 3001

C9orf3 (9q22.32)
HMGA2 (12q14.3)
INSR $(19 \mathrm{p} 13.3)$
LHCGR $(2 \mathrm{p} 16.3)$
RAB5B and SUOX
SUMO1P1 and ZN 12.1$)$
TOX3 $16 \mathrm{q} 12.1)$
YAP1 (11q22.1)
None
GYS2
C9orf3
DENND1A
THADA
YAP1
Meta-analysis
C9Orf3
DENND1A
FSHR
LHCGR
RAB5B and SUOX
SUMO1P1
THADA
YAP1

rs3802457

rs2272046

rs205980

rs2268361

rs705702

rs6022786

rs4784165

rs1894116

None

rs6487237, rs7485509, rs10841843

rs4385527

rs10986105

rs12468395, rs12478601

rs1894116

rs2349415, rs4385527

rs10818854, rs10986105

rs2268361

rs13405728

rs1894116

rs705702, rs6022786

rs12468394, rs12478601

rs3802457

GWAS, genome-wide association study; $L H C G R$, luteinising hormone/human chorionic gonadotrophin receptor gene; THADA, thyroid adenomaassociated gene; DENND1A, gene modifier of guanine; C9orf3, chromosome 9 open reading frame 3; YAP1, yes-associated protein1; RAB5B, oncogene family; SUOX, sulphite oxidase gene; HMGA2, high-mobility group AT-hook2; TOX3, TOX high-mobility group box family member3; $I N S R$, insulin receptor gene; ZNF217, zinc finger protein 217; GYS2, glycogen synthase 2 (liver); FSHR, follicle-stimulating hormone receptor gene. ${ }^{\mathrm{a}} \mathrm{All}$ of the studies mentioned were case-control studies. This table includes only the genome-wide association studies on women with PCOS. 
Genetic studies of PCOS also include the analysis of structural/anatomical changes in chromosomes (changes in non-coding sequences) based on the assessment of telomere length. The telomere is a structure located at the end of the chromosome that is involved in chromatin organisation, the control of cell proliferation, the preservation of genome integrity and the stability and prevention of chromosome fusion (Allsopp et al. 1992). Physiologically, telomere length decreases with ageing. However, this process can be accelerated by cardiovascular disease, SAH, hypercholesterolaemia and type 2 DM, conditions that are associated with an inflammatory and oxidative environment (Fuster \& Andres 2006). Because women with PCOS are at greater risk for these clinical and metabolic conditions, and because PCOS is associated with inflammation and oxidative stress (Cussons et al. 2006), telomere shortening may be another mechanism associated with the pathogenesis of PCOS and its comorbidities. In this context, a Chinese group showed that women with PCOS have shorter telomeres than do subjects without PCOS in a singleassessment, cross-sectional study of women of various ages (PCOS: $n=698$ vs control: $n=611$ ) (Li et al. 2014). These data were not confirmed by other investigators who assessed Brazilian women with PCOS (PCOS: $n=150$ vs control: $n=124$ ) (Pedroso et al. 2014). The discrepancy might occur because the two studies compared women at different stages of life (reproductive age and menopause) and the assessments of women at reproductive age might have occurred too early to detect differences in telomere length between women with PCOS and those without PCOS. Birth cohort studies may be more suitable for elucidating the dynamic of telomere shortening because this methodology can assess the same population at different stages of life (lifespan assessment).

\section{Role of developmental programming in the pathogenesis of PCOS}

Developmental programming refers to changes in gene expression that result from the presence of increased levels of steroid hormones in the foetal circulation at critical stages of foetal development and that result in permanent structural and functional modifications of the body organs. This phenomenon might be caused either by the presence of excess glucocorticoids (resulting from foetal hypoxia and IUGR) (Wells 2011, Longo et al. 2013) or by the elevation of maternal androgen levels during pregnancy (Padmanabhan \& Veiga-Lopez 2011, Escobar-Morreale et al. 2014). In addition to anatomic and functional changes in organs and organ systems, developmental programming might also be associated with the programming of endocrine pathways and thus also with clinical, metabolic and reproductive changes during postnatal life.
Changes in gene expression are necessary for the physiological development of the foetus. However, under unfavourable intra-uterine conditions, excessive steroid levels might induce alterations in gene expression that can result in epigenetic modifications (hereditary changes in the genome that do not involve any alteration in the DNA nucleotide sequence and are transmitted during cell division). DNA methylation, in which the chemical structure of cytosine is modified through the addition of a methyl group $(\mathrm{CH} 3)$, is one such epigenetic alteration (Li \& Huang 2008). Xu et al. (2011) have shown that exposure of foetal female monkeys to testosterone excess changes the epigenome of their visceral fat cells. Therefore, epigenetic alterations might represent the molecular basis of developmental programming related to the reproductive and metabolic phenotypes exhibited by women with PCOS over the course of their lives (Wang et al. 2014).

\section{Developmental programming by glucocorticoid excess}

The proper growth of the foetus results from a balance between anabolic and catabolic processes that occur during the functional maturation and differentiation of foetal organs and tissues. If foetal hypoxia develops during this period because of dietary restrictions and/or maternal or placental disease, the catabolic process will predominate, which results in IUGR and ultimately an SGA newborn. To assure survival and reduce energy expenditure ('thrifty phenotype') (Barker 1995), foetal blood flow is redirected to essential organs (heart, brain and adrenal glands) in a phenomenon called centralisation. Consequently, there is an increased production of glucocorticoids because of the hyperactivity of the hypothalamic-pituitary-adrenal (HPA) axis, which results in epigenetic modifications (Wells 2011, Longo et al. 2013).

Clinical assessments of the effects of developmental programming that result from glucocorticoid excess on the development of disease at later stages of life are hindered by the multifactorial aetiology of most reproductive, metabolic and cardiovascular diseases. However, studies with experimental animals have found that foetuses with IUGR caused by placental insufficiency or maternal malnutrition were born SGA and that these animals showed a predisposition to developing pathologies in postnatal life after compensatory growth during the first 2 years of life (Bloomfield et al. 2003, Reynolds 2012). Clinical data show that compensatory growth might also be associated with the development of comorbidities in humans, such as precocious puberty (Ibáñez et al. 1998), SAH (Elting et al. 2001), cardiovascular disease (Bonamy et al. 2008), type 2 DM, glucose intolerance (Willemsen et al. 2008), dyslipidaemia, obesity (Martinez-Aguayo et al. 2007), 
metabolic syndrome (Jaquet et al. 2005) and PCOS (Pandolfi et al. 2008, Melo et al. 2010, Hizli et al. 2012). Thus, children born SGA would exhibit a clinical marker of developmental programming by glucocorticoids associated with the development of PCOS and its associated comorbidities, although SGA may also be constitutional (variation of normal).

\section{Developmental programming by androgen excess}

In addition to elevated glucocorticoid levels, hyperactivity of the HPA axis secondary to IUGR might also favour the occurrence of hyperandrogenism resulting from overactivity of the adrenal gland. Excessive levels of adrenal androgens may alter gene expression in such a way as to favour the development of the reproductive and metabolic phenotypes of PCOS in animals (Reynolds 2012). Among other factors, this mechanism might account for the higher risk of PCOS and associated clinical/metabolic conditions exhibited by the offspring of mothers with PCOS (Padmanabhan \& Veiga-Lopez 2011). Adrenal androgen excess in the maternal circulation occurs in the absence of IUGR (a characteristic that has been shown in animal models) (Zhou et al. 2005), and hyperandrogenism might be consequence of obesity, DM, IR (Escobar-Morreale et al. 2014), PCOS and/or any other condition associated with androgen excess (Sir-Petermann et al. 2009).

Obesity (Chandrasekaran et al. 2014), DM, IR and excessive weight gain during pregnancy (Xiang et al. 2015) are predictors of large-for-gestational-age (LGA) offspring. Because these conditions may also be associated with hyperandrogenism (Macut et al. 2014), LGA babies might exhibit a higher risk for PCOS via developmental programming by androgen excess, but this hypothesis remains to be confirmed through clinical studies. Mumm et al. (2013) found that the risk of PCOS was not higher among LGA female babies of mothers with type 2 DM. However, those authors used data they had located through a search of medical records using International Classification of Diseases (ICD) codes that was performed before the publication of any consensus on the diagnostic criteria for PCOS.

Based on the results of experiments conducted in animals, it has been established that the stage of pregnancy during which exposure to androgen excess occurs is crucial for determining the reproductive and metabolic phenotypes associated with PCOS. PCOS-like reproductive disorders were found to predominate in animals that had been treated with androgens during both the first and second halves of pregnancy, whereas problems related to glucose metabolism and visceral obesity predominated in animals that had been treated with androgens during the first half of pregnancy (Abbott et al. 2005; Table 2).
Table 2 Main reproductive and metabolic disorders associated with developmental programming by androgen excess in monkeys ${ }^{\mathrm{a}}$.

\begin{tabular}{ll}
\hline Reproductive & Metabolic \\
\hline Anovulation & Insulin resistance \\
Ovarian hyperandrogenism & Glucose intolerance \\
Polycystic ovaries & Type 2 diabetes mellitus \\
LH hypersecretion & Visceral obesity \\
Infertility & Dyslipidaemia \\
\hline
\end{tabular}

$\mathrm{LH}$, luteinising hormone.

aPCOS-like reproductive disorders occur in the offspring of animals treated with androgens in both the first and second halves of pregnancy, whereas PCOS-related metabolic disorders appear in the offspring of animals treated with androgens at the beginning of pregnancy.

\section{Developmental programming related to PCOS manifestations: aspects relevant to childhood and adolescence}

Approximately $90 \%$ of SGA children present rapid growth and weight gain during the first 2 years of life (compensatory growth). At the end of this period, the growth curves and development of these children are similar to the patterns observed in children born AGA (Albertsson-Wikland et al. 1998). Compensatory growth is associated with hyperinsulinaemia, central obesity and adipose tissue dysfunction in childhood, factors that can alter the distribution of body fat and accelerate the onset of adrenarche and puberty, especially pubarche (Ibáñez et al. 1998).

During the peripubertal period, increased levels of leptin caused by dysfunctions in adipose tissue are associated with the hypersecretion of $\mathrm{LH}$ and the development of ovarian hyperandrogenism. Consequently, anovulatory cycles are more frequently observed in women who were born SGA (Ibáñez et al. 2002), which suggests that these women have a higher risk of developing PCOS. In addition, insulin acts on the ovarian theca through insulin-like growth factor 1 (IGF1), which results in increased levels of ovarian androgens. This process occurs because hyperinsulinaemia decreases the hepatic synthesis of IGF binding protein 1 (IGFBP1), which thus increases the free fraction of IGF1 (Poretsky et al. 1999). A reduction in the hepatic synthesis of SHBG, with a resulting increase in the levels of the free fraction of circulating androgens in SGA women, is another process that may be associated with hyperinsulinaemia (lbáñez et al. 1998, 2002). Foetuses of animals exposed to androgen excess at the beginning of pregnancy may also exhibit an increased risk of hyperinsulinaemia and visceral obesity in infancy (Escobar-Morreale et al. 2014). Although developmental programming by androgen excess might be associated with IUGR in rodents (Sathishkumar et al. 2011) and sheep (Beckett et al. 2014) and with low birth weight (LBW), these characteristics are not frequently found in that process in non-human primate models for PCOS (Abbott et al. 2010). 


\section{Development programming related to PCOS manifestations: aspects relevant to reproductive age}

The hyperinsulinaemia and hyperandrogenism observed during and after the immature stage of development of the HPA in SGA women, which is associated with a higher frequency of anovulatory cycles (Ibáñez et al.
2002), characterises SGA women as a group that is at risk for developing PCOS at reproductive age (Fig. 3). During the third decade of life, this risk can be twice as high in women born SGA as it is in women born AGA (Melo et al. 2010). However, PCOS does not occur in all women born SGA (Laitinen et al. 2003, Mumm et al. 2013), and
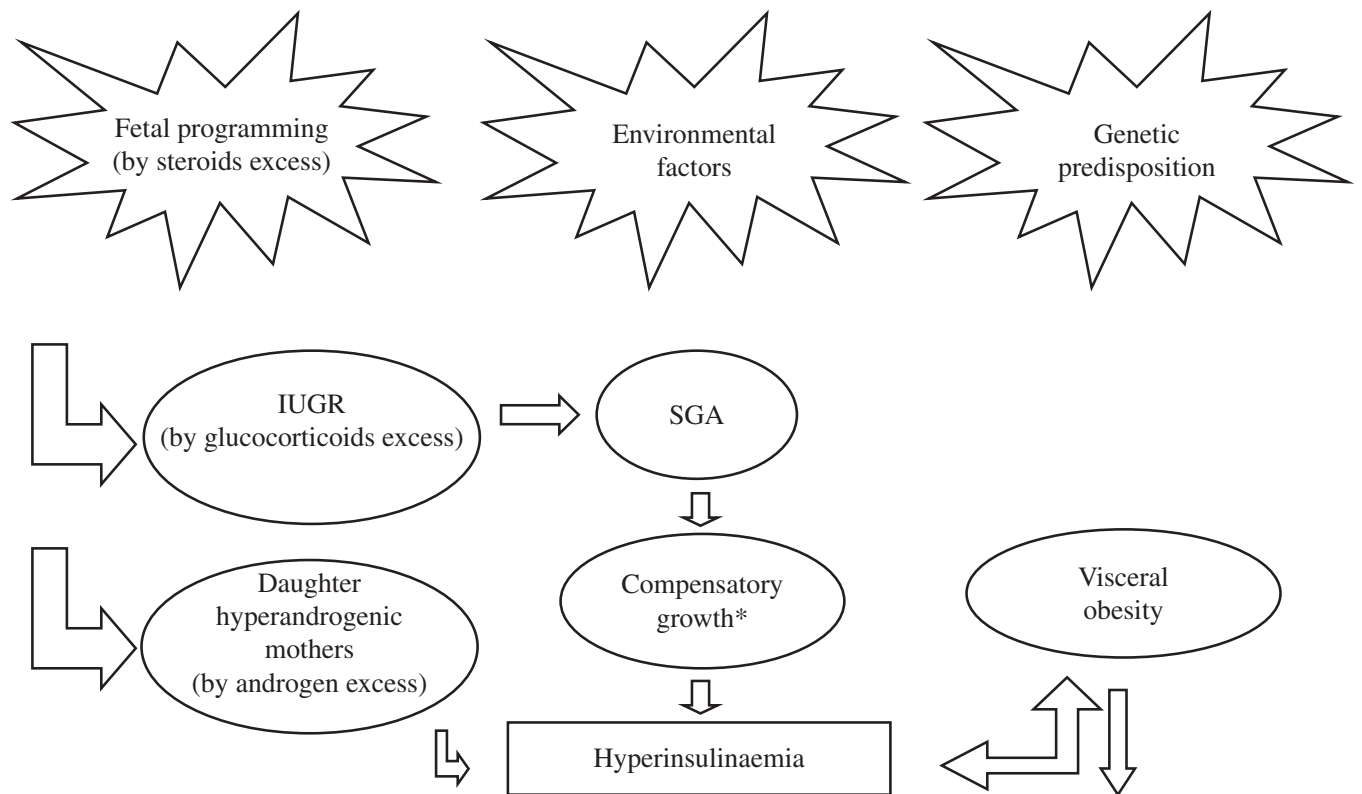

П
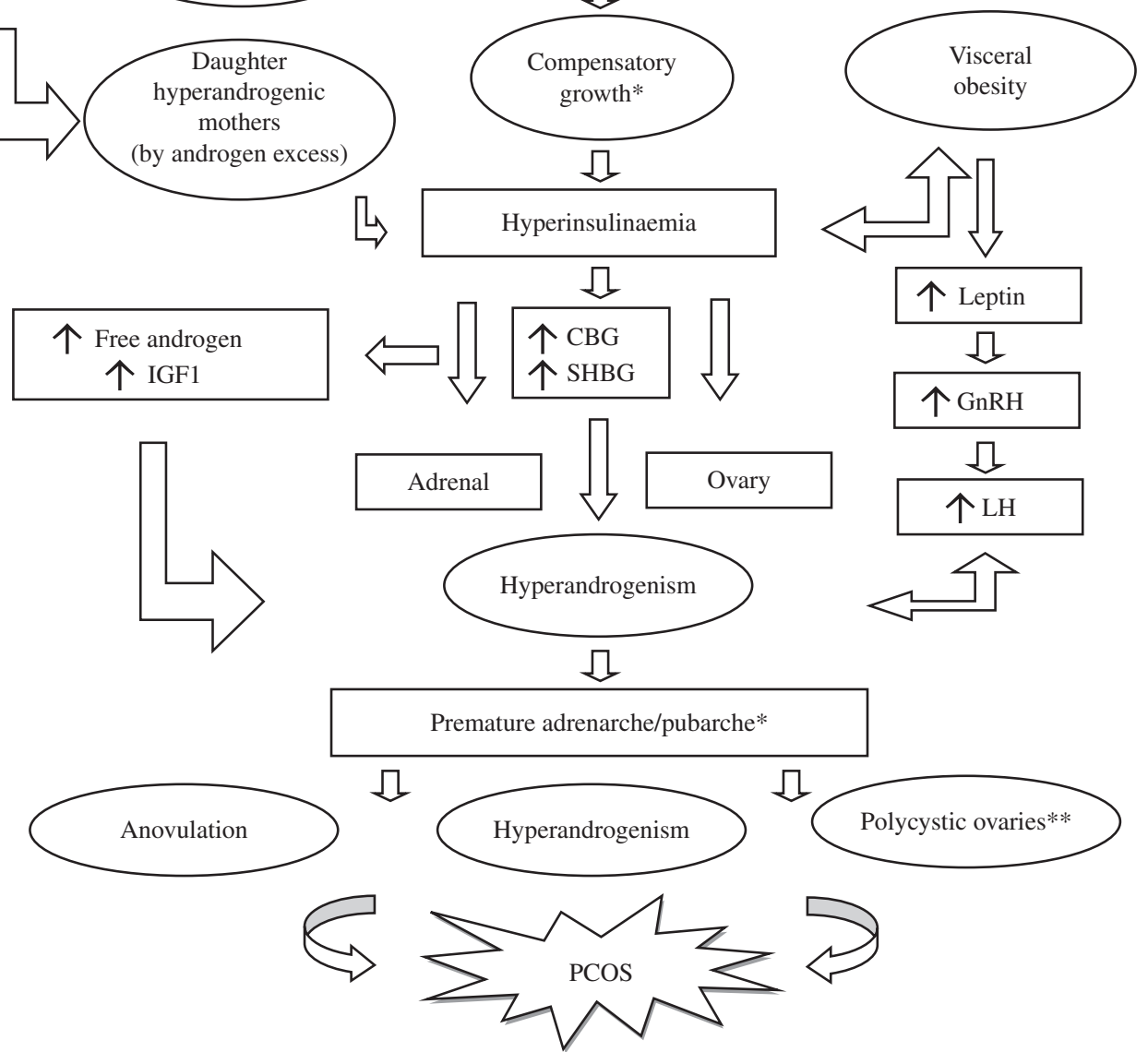

Figure 3 Aetiology of PCOS: multifactorial assessment from the intra-uterine environment to reproductive age. *Events associated only with born SGA, which suggests later phenotypes of developmental programming by glucocorticoid excess. ${ }^{* *}$ Characteristic shown only in daughters of hyperandrogenic mothers, which suggests manifestation of developmental programming by androgen excess. The other features may be associated with the intra-uterine effects of both steroids. IUGR, intra-uterine growth restriction; SGA, small for gestational age; CBG, corticosteroid binding globulin; SHBG, sex hormone-binding globulin; GnRH, gonadotrophin-releasing hormone; LH, luteinising hormone; IGF1, insulin-like growth factor 1; PCOS, polycystic ovary syndrome. 
women born AGA or daughters of women without PCOS can also develop this disorder, which suggests a multifactorial aetiology of PCOS (Melo et al. 2010).

Because women born SGA and the daughters of hyperandrogenic women show higher frequencies of hyperinsulinaemia, visceral obesity, adipose tissue dysfunction and IR during childhood, these characteristics could be considered early clinical markers of the development of SAH, dyslipidaemia, metabolic syndrome and type 2 DM related to PCOS. Typically, these metabolic comorbidities are more prevalent after the age of 40 in the general population without PCOS. However, PCOS women, especially obese women with family histories of type 2 DM, histories of gestational diabetes, acanthosis nigricans or irregular menstrual cycles and hyperandrogenism, begin to present these comorbidities beginning in the fourth decade of life (Elting et al. 2001, Moran et al. 2010).

In addition to the multiple aetiological aspects of PCOS, ethnicity and geographical region are relevant factors in the study of birth weight and the development of PCOS. Although SGA women in Brazil (Melo et al. 2010) and those with LBW in Italy (Pandolfi et al. 2008) and Turkey (Hizli et al. 2012) present a higher risk for developing PCOS, these findings were not confirmed in individuals from the USA (Legro et al. 2010), UK (Cresswell et al. 1997, Michelmore et al. 2001, Shayeb et al. 2014), The Netherlands (Sadrzadeh et al. 2003), Finland (Laitinen et al. 2003), Spain (Ibáñez et al. 2008) or Denmark (Mumm et al. 2013). One study conducted in Australia analysed birth weight as a continuous variable and found that each $100 \mathrm{~g}$ increase in birth weight increased the risk of hyperandrogenism. The authors of that study also found that the subjects' thinness was related to PCOS symptoms and to IR (Davies et al. 2012; Table 3). These apparent regional differences may result from the limitations of these studies, which include the use of varying definitions of PCOS (Cresswell et al. 1997, Laitinen et al. 2003, Sadrzadeh et al. 2003, Ibáñez et al. 2008, Hizli et al. 2012, Mumm et al. 2013), the inclusion of women using hormonal contraceptives (Ibáñez et al. 2007, Davies et al. 2012, Mumm et al. 2013), the small numbers of participants (Ibáñez et al. 2001, Pandolfi et al. 2008), the use of self-reported birth data (Laitinen et al. 2003, Sadrzadeh et al. 2003, Legro et al. 2010, Hizli et al. 2012), the inclusion of women with immature HPG axes (Ibáñez et al. 2001) and the absence of compensatory growth assessments (Cresswell et al. 1997, Michelmore et al. 2001, Laitinen et al. 2003, Sadrzadeh et al. 2003, Ibáñez et al. 2008, Pandolfi et al. 2008, Legro et al. 2010, Melo et al. 2010, Hizli et al. 2012, Mumm et al. 2013, Shayeb et al. 2014). The use of birth weight classifications as an exposure factor across studies was perhaps the most important limitation, because not all of the studies adjusted the subjects' birth weight for GA. For that reason, some of the studies included preterm newborn infants. This feature might indicate the presence of selection bias (Cresswell et al. 1997, Michelmore et al. 2001, Sadrzadeh et al. 2003, Ibáñez et al. 2008, Legro et al. 2010, Hizli et al. 2012, Mumm et al. 2013, Shayeb et al. 2014), especially considering that the functional maturation of organs and tissues of a preterm newborn is completed during postnatal life (Ben 2008).

There are two main birth weight classifications: i) the classification of birth weight based on GA (AGA: birth weight between P10 and P90 for GA; SGA: birth weight below P10 for GA; LGA: birth weight above P90 for GA), which is the most frequently used classification to confirm IUGR using postnatal data (birth weight, GA and newborn sex), can be used to determine the effects of foetal growth deficits regardless of prematurity (Battaglia \& Lubchenco 1967) and is crucial for reducing bias (prematurity, for example) in the interpretation of results; and ii) the classification of birth weight independent of GA (macrossomic: birth weight $\geq 4000$ g; appropriate: 3000-3999 g; inadequate: 2500-2999 g; LBW: 1500-2499 g; very LBW <1500 g; extremely LBW: <1000 g) (FIGO 1977). This information is an important health indicator that reflects the living conditions, nutrition and access to healthcare services in a population, which is extremely important when prenatal data are not available (Paneth 1995). However, birth weight data alone cannot determine preterm individuals; thus, this classification is inappropriate for studying the relationship between birth weight and the prevalence of disease at different stages of life. For example, a newborn weighing $2300 \mathrm{~g}$ can be either a preterm AGA newborn or a full-term SGA newborn.

\section{Development programming related to PCOS manifestations: aspects relevant to menopause}

Subclinical cardiovascular disease is common in reproductive-age women with PCOS (increased carotid intima-media thickness, reduced arterial elasticity and calcification of the coronary artery and aorta), regardless of the presence of obesity, IR or SAH (Talbott et al. 2004, Luque-Ramírez et al. 2007). The characteristics associated with early exposure to cardiovascular risk factors in inflammatory and oxidative environments during the reproductive years suggest an increased risk of cardiovascular events for patients in menopause and for elderly patients with PCOS (Cussons et al. 2006). However, the multifactorial aetiology of cardiovascular disease and the lack of well-designed prospective studies in which these women were assessed at different stages of life make conclusions regarding this possible association difficult. Although currently available evidence suggests that women with PCOS have twice the risk for cardiovascular events than that of the population without PCOS, this finding has some limitations: i) the lack of a 


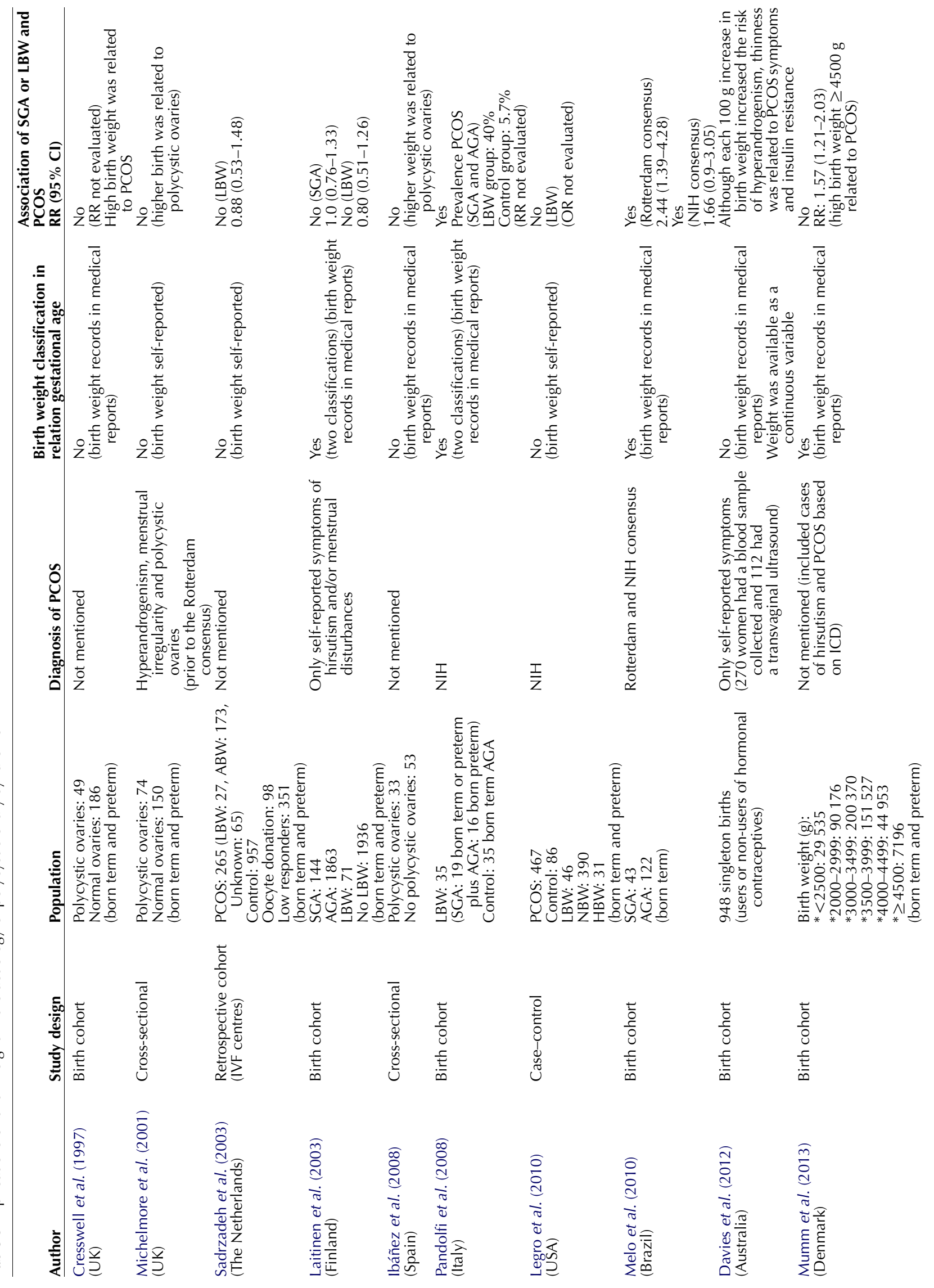




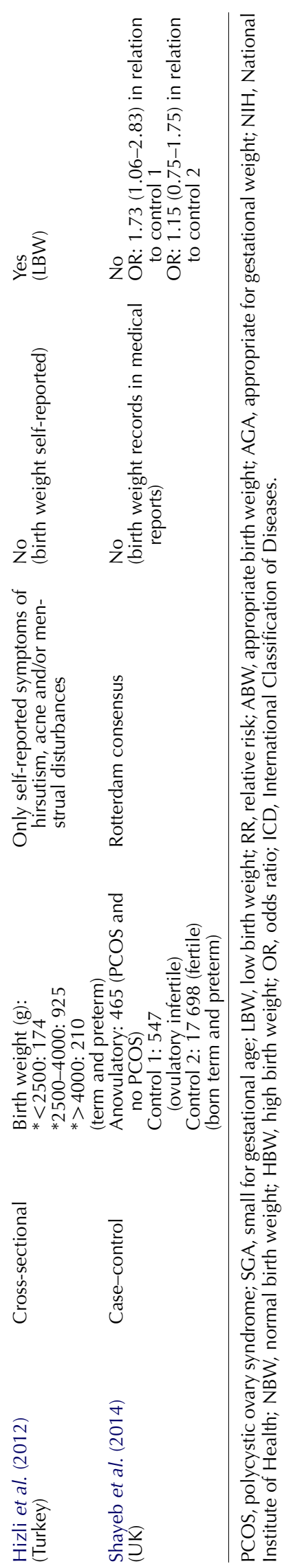

standardised diagnosis of PCOS; and ii) the lack of case stratification as fatal and non-fatal (De Groot et al. 2011). When such stratification was performed, an increased risk of non-fatal stroke was observed in menopausal PCOS women (OR, 1.94; 95\% Cl, 1.19-3.17) (Anderson et al. 2014), but no increased risk for acute myocardial infarction and/or mortality caused by cardiovascular events in women aged 61-79 years was observed during a 21-year follow-up (Schmidt et al. 2011). However, these studies did not provide proper external validity to allow these findings to be extrapolated to menopausal/ elderly PCOS women of other ethnic groups who might have been exposed to different environmental factors.

Although the aetiology of cardiovascular disorders is multifactorial, visceral obesity and hyperinsulinaemia play an important role in the development of cardiovascular events in women with PCOS. Visceral obesity and increased insulin levels may promote adipose tissue dysfunction and the subsequent elevation of inflammatory and metabolic markers that have an atherogenic effect in women of reproductive age (Melo et al. 2014). This adipose tissue dysfunction is associated with an increased prevalence of $\mathrm{SAH}$, dyslipidaemia, metabolic syndrome, IR, type $2 \mathrm{DM}$ and maintenance of hyperandrogenism, and it promotes endothelial dysfunction in inflammatory, oxidative and procoagulant environments, so it thus favours the occurrence of arterial thrombosis during menopause (Fig. 4; Cussons et al. 2006). However, regional studies are needed to determine the profile of morbidity and mortality of specific populations and to establish effective preventive interventions for PCOS and the metabolic and cardiovascular changes with which it is associated.

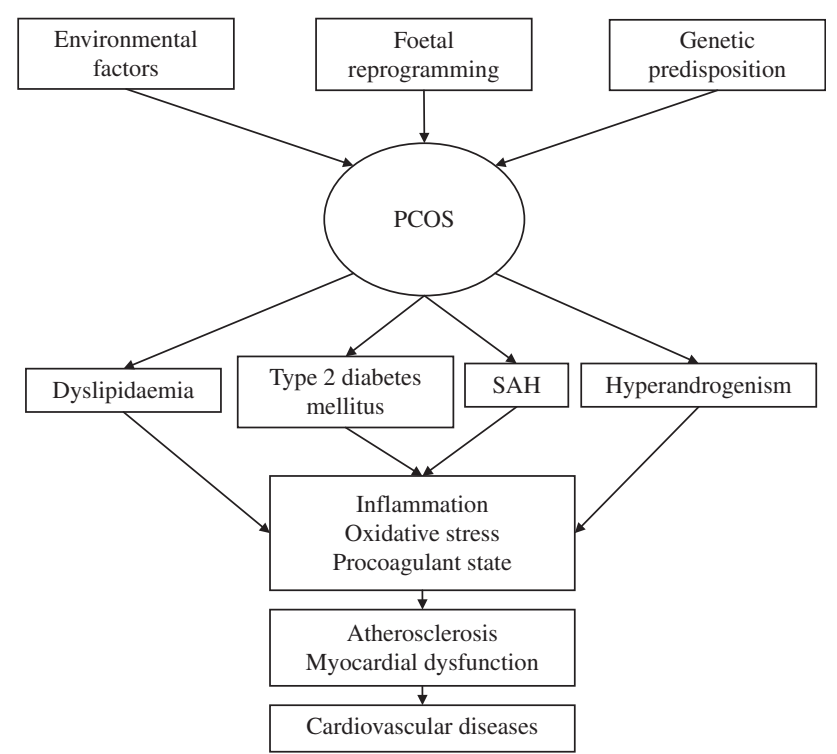

Figure 4 Pathogenesis of PCOS: evolutionary and multifactorial assessment from the reproductive age to menopause/senescence. Modified from Cussons et al. (2006). SAH, systemic arterial hypertension; IR, insulin resistance. 


\section{Conclusion}

PCOS has a multifactorial aetiology with ethnic and regional aspects. Although being born SGA or being the child of a hyperandrogenic mother might be considered clinical markers for developmental programming by steroids, individuals who are not exposed to excess steroids and the offspring of non-hyperandrogenic mothers can also develop PCOS. This indicates that postnatal environmental factors and genetic predisposing factors also lie at the origin of this disorder. Follow-up studies that assess the same population at different stages of life will facilitate a better understanding of the interactions between environmental, genetic and intrauterine factors in the development of PCOS and its comorbidities over a lifespan.

\section{Declaration of interest}

The authors declare that there is no conflict of interest that could be perceived as prejudicing the impartiality of the review.

\section{Funding}

This review did not receive any specific grant from any funding agency in the public, commercial or not-for-profit sector.

\section{References}

Abbott DH, Dumesic DA \& Franks S 2002 Developmental origin of polycystic ovary syndrome - a hypothesis. Journal of Endocrinology 174 1-5. (doi:10.1677/joe.0.1740001)

Abbott DH, Barnett DK, Bruns CM \& Dumesic DA 2005 Androgen excess fetal programming of female reproduction: a developmental aetiology for polycystic ovary syndrome? Human Reproduction Update 11 357-374. (doi:10.1093/humupd/dmi013)

Abbott DH, Bruns CR, Barnett DK, Dunaif A, Goodfriend TL, Dumesic DA \& Tarantal AF 2010 Experimentally induced gestational androgen excess disrupts glucoregulation in rhesus monkey dams and their female offspring. American Journal of Physiology. Endocrinology and Metabolism 299 E741-E751. (doi:10.1152/ajpendo.00058.2010)

Albertsson-Wikland K, Boguszewski M \& Karlberg J 1998 Children born small-for-gestational age: postnatal growth and hormonal status. Hormone Research 49 7-13. (doi:10.1159/000053080)

Allsopp RC, Vaziri H, Patterson C, Goldstein S, Younglai EV, Futcher AB, Greider CW \& Harley CB 1992 Telomere length predicts replicative capacity of human fibroblasts. PNAS 89 10114-10118. (doi:10.1073/ pnas.89.21.10114)

Amsterdam ESHRE/ASRM-Sponsored 3rd PCOS Consensus Workshop Group 2012 Consensus on women's health aspects of polycystic ovary syndrome (PCOS). Human Reproduction 27 14-24. (doi:10.1093/ humrep/der396)

Anderson SA, Barry JA \& Hardiman PJ 2014 Risk of coronary heart disease and risk of stroke in women with polycystic ovary syndrome: a systematic review and meta-analysis. International Journal of Cardiology $\mathbf{1 7 6}$ 486-487. (doi:10.1016/j.ijcard.2014.06.079)

Azziz R, Carmina E, Dewailly D, Diamanti-Kandarakis E, EscobarMorreale HF, Futterweit W, Janssen OE, Legro RS, Norman RJ, Taylor AE et al. 2006 Positions statement: criteria for defining polycystic ovary syndrome as a predominantly hyperandrogenic syndrome: an Androgen Excess Society guideline. Journal of Clinical Endocrinology and Metabolism 91 4237-4245. (doi:10.1210/jc.2006-0178)
Barker DJ 1995 The fetal and infant origins of disease. European Journal of Clinical Investigation 25 457-463. (doi:10.1111/j.13652362.1995.tb01730.x)

Battaglia FC \& Lubchenco LO 1967 A practical classification of newborn infants by weight and gestational age. Journal of Pediatrics 71 159-163. (doi:10.1016/S0022-3476(67)80066-0)

Beckett EM, Astapova O, Steckler TL, Veiga-Lopez A \& Padmanabhan V 2014 Developmental programing: impact of testosterone on placental differentiation. Reproduction 148 199-209. (doi:10.1530/REP-14-0055)

Ben XM 2008 Nutritional management of newborn infants: practical guidelines. World Journal of Gastroenterology 14 6133-6139. (doi:10.3748/wjg.14.6133)

Bloomfield FH, Oliver MH, Giannoulias CD, Gluckman PD, Harding JE \& Challis JR 2003 Brief undernutrition in late-gestation sheep programs the hypothalamic-pituitary-adrenal axis in adult offspring. Endocrinology 144 2933-2940. (doi:10.1210/en.2003-0189)

Bonamy AK, Norman M \& Kaijser M 2008 Being born too small, too early, or both: does it matter for risk of hypertension in the elderly? American Journal of Hypertension 21 1107-1110. (doi:10.1038/ajh.2008.241)

Chandrasekaran S, Bastek JA, Turitz AL \& Durnwald C 2014 A prediction score to assess the risk of delivering a large-for-gestational-age infant among obese women. Journal of Maternal-Fetal \& Neonatal Medicine 27 1-17. (doi:10.3109/14767058.2014.991709)

Chen ZJ, Zhao H, He L, Shi Y, Qin Y, Shi Y, Li Z, You L, Zhao J, Liu J et al. 2011 Genome-wide association study identifies susceptibility loci for polycystic ovary syndrome on chromosome $2 \mathrm{p} 16.3,2 \mathrm{p} 21$ and $9 \mathrm{q} 33.3$. Nature Genetics 43 55-59. (doi:10.1038/ng.732)

Cresswell JL, Barker DJ, Osmond C, Egger P, Phillips DI \& Fraser RB 1997 Fetal growth, length of gestation, and polycystic ovaries in adult life. Lancet 350 1131-1135. (doi:10.1016/S0140-6736(97)06062-5)

Cussons AJ, Stuckey BG \& Watts GF 2006 Cardiovascular disease in the polycystic ovary syndrome: new insights and perspectives. Atherosclerosis 185 227-239. (doi:10.1016/j.atherosclerosis.2005.10.007)

Daan NM, Louwers YV, Koster MP, Eijkemans MJ, de Rijke YB, Lentjes EW, Fauser BC \& Laven JS 2014 Cardiovascular and metabolic profiles amongst different polycystic ovary syndrome phenotypes: who is really at risk? Fertility and Sterility 102 1444-1451. (doi:10.1016/j.fertnstert. 2014.08.001)

Davies MJ, March WA, Willson KJ, Giles LC \& Moore VM 2012 Birthweight and thinness at birth independently predict symptoms of polycystic ovary syndrome in adulthood. Human Reproduction 27 1475-1480. (doi:10. 1093/humrep/des027)

Diamanti-Kandarakis E, Kandarakis H \& Legro RS 2006 The role of genes and environment in the etiology of PCOS. Endocrine 30 19-26. (doi:10.1385/ENDO:30:1:19)

Elting MW, Korsen TJ, Bezemer PD \& Schoemaker J 2001 Prevalence of diabetes mellitus, hypertension and cardiac complaints in a follow-up study of a Dutch PCOS population. Human Reproduction 16 556-560. (doi:10.1093/humrep/16.3.556)

Escobar-Morreale HF, Luque-Ramírez M \& San Millan JL 2005 The molecular-genetic basis of functional hyperandrogenism and the polycystic ovary syndrome. Endocrine Reviews 26 251-282. (doi:10.1210/er.2004-0004)

Escobar-Morreale HF, Alvarez-Blasco F, Botella-Carretero JI \& LuqueRamírez M 2014 The striking similarities in the metabolic associations of female androgen excess and male androgen deficiency. Human Reproduction 29 2083-2091. (doi:10.1093/humrep/deu198)

FIGO 1977 World Health Organization recommended definitions, terminology and format for statistical tables related to the perinatal period and use of a new certificate for cause of perinatal deaths. Modifications recommended by FIGO as amended October 14, 1976. Acta Obstetricia et Gynecologica Scandinavica 56 247-253.

Fuster JJ \& Andres V 2006 Telomere biology and cardiovascular disease. Circulation Research 99 1167-1180. (doi:10.1161/01.RES.0000251281. 00845.18)

Galluzzo A, Amato MC \& Giordano C 2008 Insulin resistance and polycystic ovary syndrome. Nutrition, Metabolism, and Cardiovascular Diseases 18 511-518. (doi:10.1016/j.numecd.2008.05.004)

Goodarzi MO, Jones MR, Li X, Chua AK, Garcia OA, Chen YD, Krauss RM, Rotter JI, Ankener W, Legro RS et al. 2012 Replication of association of 
DENND1A and THADA variants with polycystic ovary syndrome in European cohorts. Journal of Medical Genetics 49 90-95. (doi:10.1136/ jmedgenet-2011-100427)

de Groot PC, Dekkers OM, Romijn JA, Dieben SW \& Helmerhorst FM 2011 PCOS, coronary heart disease, stroke and the influence of obesity: a systematic review and meta-analysis. Human Reproduction Update 14 495-500. (doi:10.1093/humupd/dmr001)

Hizli D, Köşüş A, Köşüş N, Kamalak Z, Ak D \& Turhan NÖ 2012 The impact of birth weight and maternal history on acne, hirsutism, and menstrual disorder symptoms in Turkish adolescent girls. Endocrine 41 473-478. (doi:10.1007/s12020-011-9575-x)

Hwang JY, Lee EJ, Jin Go M, Sung YA, Lee HJ, Heon Kwak S, Jang HC, Soo Park K, Lee HJ, Byul Jang H et al. 2012 Genome-wide association study identifies GYS2 as a novel genetic factor for polycystic ovary syndrome through obesity-related condition. Journal of Human Genetics $\mathbf{5 7}$ 660-664. (doi:10.1038/jhg.2012.92)

Ibáñez L, Potau N, Francois I \& de Zegher F 1998 Precocious pubarche, hyperinsulinism, and ovarian hyperandrogenism in girls: relation to reduced fetal growth. Journal of Clinical Endocrinology and Metabolism 83 3558-3562. (doi:10.1210/jcem.83.10.5205)

Ibáñez L, Valls C, Potau N, Marcos MV \& de Zegher F 2001 Polycystic ovary syndrome after precocious pubarche: ontogeny of the low-birthweight effect. Clinical Endocrinology 55 667-672. (doi:10.1111/j.1365-2265. 2001.01399.x)

Ibáñez L, Potau N, Ferrer A, Rodriguez-Hierro F, Marcos MV \& de Zegher F 2002 Reduced ovulation rate in adolescent girls born small for gestational age. Journal of Clinical Endocrinology and Metabolism 87 3391-3393. (doi:10.1210/jcem.87.7.8657)

Ibáñez L, Jaramillo A, Enríquez G, Miró E, López-Bermejo A, Dunger D \& de Zegher F 2007 Polycystic ovaries after precocious pubarche: relation to prenatal growth. Human Reproduction 22 395-400. (doi:10.1093/ humrep/del395)

Ibáñez L, López-Bermejo A, Callejo J, Torres A, Cabré S, Dunger D \& de Zegher F 2008 Polycystic ovaries in non-obese adolescents and young women with ovarian androgen excess: relation to prenatal growth. Journal of Clinical Endocrinology and Metabolism 93 196-199. (doi:10. 1210/jc.2007-1800)

Jaquet D, Deghmoun S, Chevenne D, Collin D, Czernichow P \& LevyMarchal C 2005 Dynamic change in adiposity from fetal to postnatal life is involved in the metabolic syndrome associated with reduced fetal growth. Diabetologia 48 849-855. (doi:10.1007/s00125-005-1724-4)

Jones MR, Chua AK, Mengesha EA, Taylor KD, Chen YD, Li X, Krauss RM, Rotter JI, Reproductive Medicine Network, Legro RS et al. 2012 Metabolic and cardiovascular genes in polycystic ovary syndrome: a candidate-wide association study (CWAS). Steroids 77 317-322. (doi:10. 1016/j.steroids.2011.12.005)

Laitinen J, Taponen S, Martikainen H, Pouta A, Millwood I, Hartikainen AL, Ruokonen A, Sovio U, McCarthy MI, Franks S et al. 2003 Body size from birth to adulthood as a predictor of self-reported polycystic ovary syndrome symptoms. International Journal of Obesity and Related Metabolic Disorders 27 710-715. (doi:10.1038/sj.ijo.0802301)

Legro RS, Roller RL, Dodson WC, Stetter CM, Kunselman AR \& Dunaif A 2010 Associations of birthweight and gestational age with reproductive and metabolic phenotypes in women with polycystic ovarian syndrome and their first-degree relatives. Journal of Clinical Endocrinology and Metabolism 95 789-799. (doi:10.1210/jc.2009-1849)

Li Z \& Huang H 2008 Epigenetic abnormality: a possible mechanism underlying the fetal origin of polycystic ovary syndrome. Medical Hypotheses 70 638-642. (doi:10.1016/j.mehy.2006.09.076)

Li Q, Du J, Feng R, Xu Y, Wang H, Sang Q, Xing Q, Zhao X, Jin L, He L et al. 2014 A possible new mechanism in the pathophysiology of polycystic ovary syndrome (PCOS): the discovery that leukocyte telomere length is strongly associated with PCOS. Journal of Clinical Endocrinology and Metabolism 99 E234-E240. (doi:10.1210/jc.2013-3685)

Longo S, Bollani L, Decembrino L, Di Comite A, Angelini M \& Stronati M 2013 Short-term and long-term sequelae in intrauterine growth retardation (IUGR). Journal of Maternal-Fetal \& Neonatal Medicine 26 222-225. (doi:10.3109/14767058.2012.715006)

Louwers YV, Stolk L, Uitterlinden AG \& Laven JS 2013 Cross-ethnic metaanalysis of genetic variants for polycystic ovary syndrome. Journal of Clinical Endocrinology and Metabolism 98 E2006-E2012. (doi:10.1210/ jc.2013-2495)
Luque-Ramírez M, Mendieta-Azcona C, Alvarez-Blasco F \& EscobarMorreale HF 2007 Androgen excess is associated with the increased carotid intima-media thickness observed in young women with polycystic ovary syndrome. Human Reproduction 22 3197-3203. (doi:10.1093/humrep/dem324)

Macut D, Antić IB \& Bjekić-Macut J 2015 Cardiovascular risk factors and events in women with androgen excess. Journal of Endocrinological Investigation 38 295-301. (doi:10.1007/s40618-014-0215-1)

Martinez-Aguayo A, Capurro T, Pena V, Iniguez G, Hernandez MI, Avila A, Salazar T, Asenjo S \& Mericq V 2007 Comparison of leptin levels, body composition and insulin sensitivity and secretion by OGTT in healthy, early pubertal girls born at either appropriate- or small-for-gestational age. Clinical Endocrinology 67 526-533. (doi:10.1111/j.1365-2265. 2007.02919.x)

Melo AS, Vieira CS, Barbieri MA, Rosa-E-Silva AC, Silva AA, Cardoso VC, Reis RM, Ferriani RA, Silva-de-Sá MF \& Bettiol H 2010 High prevalence of polycystic ovary syndrome in women born small for gestational age. Human Reproduction 25 2124-2131. (doi:10.1093/humrep/deq162)

Melo AS, Vieira CS, Romano LG, Ferriani RA \& Navarro PA 2011 The frequency of metabolic syndrome is higher among PCOS Brazilian women with menstrual irregularity plus hyperandrogenism. Reproductive Sciences 18 1230-1236. (doi:10.1177/1933719111414205)

Melo AS, Bettiol H, Silva AA, Rosa-e-Silva AC, Cardoso VC, Reis RM, Ferriani RA, Barbieri MA \& Vieira CS 2014 Small for gestational age babies are not related to changes in markers of adipose tissue dysfunction during reproductive age. Early Human Development 90 231-235. (doi:10.1016/j.earlhumdev.2014.02.004)

Michelmore K, Ong K, Mason S, Bennett S, Perry L, Vessey M, Balen A \& Dunger D 2001 Clinical features in women with polycystic ovaries: relationships to insulin sensitivity, insulin gene VNTR and birth weight. Clinical Endocrinology 55 439-446. (doi:10.1046/j.1365-2265.2001. 01375.x)

Moran LJ, Misso ML, Wild RA \& Norman RJ 2010 Impaired glucose tolerance, type 2 diabetes and metabolic syndrome in polycystic ovary syndrome: a systematic review and meta-analysis. Human Reproduction Update 16 347-363. (doi:10.1093/humupd/dmq001)

Moran LJ, Hutchison SK, Norman RJ \& Teede HJ 2011 Lifestyle changes in women with polycystic ovary syndrome. Cochrane Database of Systematic Reviews 7 CD007506. (doi:10.1002/14651858.CD007506. pub3)

Mumm H, Kamper-Jørgensen M, Nybo Andersen AM, Glintborg D \& Andersen M 2013 Birth weight and polycystic ovary syndrome in adult life: a register-based study on 523,757 Danish women born 1973-1991. Fertility and Sterility 99 777-782. (doi:10.1016/j.fertnstert.2012.11.004)

Mutharasan P, Galdones E, Peñalver Bernabé B, Garcia OA, Jafari N, Shea LD, Woodruff TK, Legro RS, Dunaif A \& Urbanek M 2013 Evidence for chromosome $2 \mathrm{p} 16.3$ polycystic ovary syndrome susceptibility locus in affected women of European ancestry. Journal of Clinical Endocrinology and Metabolism 98 E185-E190. (doi:10.1210/jc.2012-2471)

Norman RJ, Dewailly D, Legro RS \& Hickey TE 2007 Polycystic ovary syndrome. Lancet 370 685-697. (doi:10.1016/S0140-6736(07)61345-2)

Padmanabhan V \& Veiga-Lopez A 2011 Developmental origin of reproductive and metabolic dysfunctions: androgenic versus estrogenic reprogramming. Seminars in Reproductive Medicine 29 173-186. (doi:10.1055/s-0031-1275519)

Pandolfi C, Zugaro A, Lattanzio F, Necozione S, Barbonetti A, Colangeli MS, Francavilla S \& Francavilla F 2008 Low birth weight and later development of insulin resistance and biochemical/clinical features of polycystic ovary syndrome. Metabolism 57 999-1004. (doi:10.1016/j.metabol.2008.02.018)

Paneth NS 1995 The problem of low birth weight. The Future of Children/Center for the Future of Children, the David and Lucile Packard Foundation 5 19-34. (doi:10.2307/1602505)

Pedroso DC, Miranda-Furtado CL, Kogure GS, Meola J, Okuka M, Silva C, Calado RT, Ferriani RA, Keefe DL \& Dos Reis RM 2014 Inflammatory biomarkers and telomere length in women with polycystic ovary syndrome. Fertility and Sterility 103 542-547e2. (doi:10.1016/j.fertnstert.2014.10.035)

Poretsky L, Cataldo NA, Rosenwaks Z \& Giudice LC 1999 The insulinrelated ovarian regulatory system in health and disease. Endocrine Reviews 20 535-582. (doi:10.1210/edrv.20.4.0374) 
Reynolds RM 2012 Glucocorticoid excess and the developmental origins of disease: two decades of testing the hypothesis - 2012 Curt Richter Award Winner. Psychoneuroendocrinology 38 1-11. (doi:10.1016/j.psyneuen. 2012.08.012)

Rotterdam ESHRE/ASRM-Sponsored PCOS Consensus Workshop Group 2004 Revised 2003 consensus on diagnostic criteria and long-term health risks related to polycystic ovary syndrome (PCOS). Human Reproduction 19 41-47. (doi:10.1093/humrep/deh098)

Sadrzadeh S, Klip WA, Broekmans FJ, Schats R, Willemsen WN, Burger CW, Van Leeuwen FE, Lambalk CB \& OMEGA Project Group 2003 Birth weight and age at menarche in patients with polycystic ovary syndrome or diminished ovarian reserve in a retrospective cohort. Human Reproduction 18 2225-2230. (doi:10.1093/humrep/deg409)

Sathishkumar K, Elkins R, Yallampalli U, Balakrishnan M \& Yallampalli C 2011 Fetal programming of adult hypertension in female rat offspring exposed to androgens in utero. Early Human Development 87 407-414. (doi:10.1016/j.earlhumdev.2011.03.001)

Schmidt J, Landin-Wilhelmsen K, Brännström M \& Dahlgren E 2011 Cardiovascular disease and risk factors in PCOS women of postmenopausal age: a 21-year controlled follow-up study. Journal of Clinical Endocrinology and Metabolism 96 3794-3803. (doi:10.1210/jc.20111677)

Shayeb AG, Harrild K \& Bhattacharya S 2014 Birth weight and ovulatory dysfunction. British Journal of Obstetrics and Gynaecology 121 281-289. (doi:10.1111/1471-0528.12262)

Shi Y, Zhao H, Shi Y, Cao Y, Yang D, Li Z, Zhang B, Liang X, Li T, Chen J et al. 2012 Genome-wide association study identifies eight new risk loci for polycystic ovary syndrome. Nature Genetics 44 1020-1025. (doi:10.1038/ng.2384)

Sir-Petermann T, Codner E, Pérez V, Echiburú B, Maliqueo M, Ladrón de Guevara A, Preisler J, Crisosto N, Sánchez F, Cassorla F et al. 2009 Metabolic and reproductive features before and during puberty in daughters of women with polycystic ovary syndrome. Journal of Clinical Endocrinology and Metabolism 94 1923-1930. (doi:10.1210/jc.20082836)

Talbott EO, Zborowski JV, Rager JR, Boudreaux MY, Edmundowicz DA \& Guzick DS 2004 Evidence for an association between metabolic cardiovascular syndrome and coronary and aortic calcification among women with polycystic ovary syndrome. Journal of Clinical Endocrinology and Metabolism 89 5454-5461. (doi:10.1210/jc.2003-032237)

Thessaloniki ESHRE/ASRM-Sponsored PCOS Consensus Workshop Group 2008 Consensus on infertility treatment related to polycystic ovary syndrome. Human Reproduction 23 462-477.

Tian JY, Cheng Q, Song XM, Li G, Jiang GX, Gu YY \& Luo M 2006 Birth weight and risk of type 2 diabetes, abdominal obesity and hypertension among Chinese adults. European Journal of Endocrinology/European Federation of Endocrine Societies 155 601-607. (doi:10.1530/eje.1. 02265)

Vink JM, Sadrzadeh S, Lambalk CB \& Boomsma DI 2006 Heritability of polycystic ovary syndrome in a Dutch twin-family study. Journal of Clinical Endocrinology and Metabolism 91 2100-2104. (doi:10.1210/jc. 2005-1494)
Wang XX, Wei JZ, Jiao J, Jiang SY, Yu DH \& Li D 2014 Genome-wide DNA methylation and gene expression patterns provide insight into polycystic ovary syndrome development. Oncotarget 5 6603-6610.

Wells JC 2011 The thrifty phenotype: an adaptation in growth or metabolism? American Journal of Human Biology 23 65-75. (doi:10.1002/ajhb.21100)

Welt CK, Styrkarsdottir U, Ehrmann DA, Thorleifsson G, Arason G, Gudmundsson JA, Ober C, Rosenfield RL, Saxena R, Thorsteinsdottir U et al. 2012 Variants in DENND1A are associated with polycystic ovary syndrome in women of European ancestry. Journal of Clinical Endocrinology and Metabolism 97 E1342-E1347. (doi:10.1210/jc. 2011-3478)

Willemsen RH, de Kort SW, van der Kaay DC \& Hokken-Koelega AC 2008 Independent effects of prematurity on metabolic and cardiovascular risk factors in short small-for-gestational-age children. Journal of Clinical Endocrinology and Metabolism 93 452-458. (doi:10.1210/jc.20071913)

Xiang AH, Black MH, Li BH, Martinez MP, Sacks DA, Lawrence JM, Buchanan TA \& Jacobsen SJ 2015 Racial and ethnic disparities in extremes of fetal growth after gestational diabetes mellitus. Diabetologia 58 272-281. (doi:10.1007/s00125-014-3420-8)

Xu N, Kwon S, Abbott DH, Geller DH, Dumesic DA, Azziz R, Guo X \& Goodarzi MO 2011 Epigenetic mechanism underlying the development of polycystic ovary syndrome (PCOS)-like phenotypes in prenatally androgenized rhesus monkeys. PLOS ONE 6 e27286. (doi:10.1371/ journal.pone.0027286)

Yildiz BO, Yarali H, Oguz H \& Bayraktar M 2003 Glucose intolerance, insulin resistance, and hyperandrogenemia in first degree relatives of women with polycystic ovary syndrome. Journal of Clinical Endocrinology and Metabolism 88 2031-2036. (doi:10.1210/jc.2002021499)

Zawadski J \& Dunaif A. Diagnostic criteria for polycystic ovary syndrome: towards a rational approach. In: Polycystic Ovary Syndrome. Dunaif A, Givens JR, Haseltine FP, Merriam GR, eds pp 377-384. Blackwell Scientific, 1992. Boston: Blackwell Scientific Publications.

de Zegher F \& Ibáñez L 2006 Prenatal growth restraint followed by catch-up of weight: a hyperinsulinemic pathway to polycystic ovary syndrome. Fertility and Sterility $\mathbf{8 6}$ S4-S5. (doi:10.1016/j.fertnstert. 2006.03.013)

Zhou R, Bird IM, Dumesic DA \& Abbott DH 2005 Adrenal hyperandrogenism is induced by fetal androgen excess in a rhesus monkey model of polycystic ovary syndrome. Journal of Clinical Endocrinology and Metabolism 90 6630-6637. (doi:10.1210/jc.2005-0691)

Received 24 September 2014

First decision 3 November 2014

Revised manuscript received 17 March 2015

Accepted 2 April 2015 